\title{
Using electricity options to hedge against financial risks of power producers
}

\author{
Salvador PINEDA ( $₫)$, Antonio J. CONEJO
}

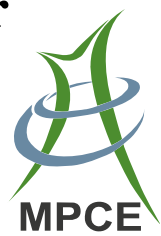

\begin{abstract}
As a consequence of competition in electricity markets, a wide variety of financial derivatives have emerged to allow market agents to hedge against risks. Electricity options and forward contracts constitute adequate instruments to manage the financial risks pertaining to price volatility or unexpected unit failures faced by power producers. A multi-stage stochastic model is described in this tutorial paper to determine the optimal forward and option contracting decisions for a risk-averse power producer. The key features of electricity options to reduce both price and availability risks are illustrated by using two examples.
\end{abstract}

Keywords Price risk, Availability risk, Stochastic programming, Forward contracts, Electricity options

\section{Introduction}

Among all energy prices, electricity prices exhibit a particularly high volatility in most day-ahead markets around the world due to the non-storability of electricity, the high variation of the demand level with the hour of the day, the day of the week, and the week of the year; the inelasticity of the electricity demand, the stepwise supply offers submitted by generating units, and the required continuous balance between the production and the consumption [1]. These

Received: 10 September 2012/Accepted: 8 May 2013/Published online: 29 August 2013

(C) The Author(s) 2013. This article is published with open access at Springerlink.com

S. PINEDA, Center for Electric Technology, Department of Electrical Engineering, Technical University of Denmark, Kgs. Lyngby, Denmark

(凹) e-mail: s.pineda@math.ku.dk

A. J. CONEJO, University of Castilla-La Mancha, Ciudad Real, Spain features are translated into the volatile profit distributions for the power producers, who usually sell most of their production in the day-ahead market. The variability of the profit of a producer caused by the volatility of the electricity price is referred to as price risk [2].

Electricity derivatives aiming at controlling the exposure of market agents to different types of risk have emerged in the restructured electricity industry [3]. These financial derivatives contribute to both share and reduce undesired risks through appropriate hedging strategies. Particularly, forward contracts are relevant derivatives within electricity markets. Forward contracts are agreements to buy/sell a fixed amount of electricity at a given price throughout a certain time interval in the future. Selling electricity through a forward contract at a fixed price allows power producers to hedge against the risk related to the volatility of pool prices [4].

On the other hand, the main disadvantage of a forward contract is that its delivery is mandatory. For instance, consider that a power producer has signed a forward contract to sell its production throughout a given time period at a pre-specified fixed price, then reducing the probability of low profits as a result of unusually low electricity prices. In that case, such a power producer is obliged to supply the agreed quantity throughout the contract delivery period. If the power producer is unable to deliver such amount of energy due to, for example, an unexpected failure of a generating unit, it must buy the missing energy in the dayahead market to comply with its contract obligation. Understandably, if the pool price happens to be higher than the contract price during the generating unit failure period, the producer is selling electricity at a cheaper price relative to the price at which such electricity is purchased and consequently, significant financial losses may occur.

Therefore, while reducing price risk, the acquisition of forward contracts to sell the electricity generated by a 
power producer increases the probability of suffering financial losses due to unexpected unit shutdowns. This risk is referred to as availability risk. Determining the optimal quantity of forward contracts to be acquired by a risk-averse power producer, taking into account the uncertainty related to both electricity pool prices and generating unit availability, is not a straightforward task [5]. Additionally, a power producer may opt for acquiring an insurance contract against unit failures [6]. Unlike forward contracts, whose main objective is to reduce the price risk faced by power producers, this type of financial product is aimed at limiting the financial losses incurred as a consequence of an unexpected outage of any of the production units owned by the power producer. Therefore, this type of contract reduces specifically the availability risk faced by power producers in exchange for a fix premium.

Alternatively to these derivatives, a producer can also sell its production through electricity options. An option is a contract that gives the holder of the option the right (not the obligation) to buy/sell a specified energy amount during a certain future time period and at a fixed price. Therefore, an option provides more flexibility than a forward contract since the holder can decide whether or not the option is exercised depending on the availability of its generating units and/or the pool price behavior. Nonetheless, whereas signing a forward contract entails no cost, there is a nonrefundable cost to acquire an option.

Previous research works pertaining to futures markets include the ones below. Reference [7] discussed the development of an option market for electricity trading. Reference [8] showed that options reduce the price risk and allow market participants to increase their potential profits. Since electricity cannot be stored, the well-known BlackScholes equation [9] is not generally an appropriate method for pricing electricity derivatives. In this context, [10] proposed a heuristic algorithm to appraise electricity options. References [11] and [12] studied the impact of options and forward contracts on the offering strategies of electricity market agents. References [13] and [14] discussed the possibility of mitigating the risks faced by retailers using electricity options. The use of an option to buy electricity by large consumers to hedge against price increases was explored in [15]. Reference [16] dealt with the design of forward contracts bundled with financial options for electricity risk management. Reference [17] proposed a model to use electricity options for demandside management. An analytical framework for the valuation of option contracts for physical delivery that enable risk-sharing among market participants is developed in [18]. The valuation of a rich family of electricity swing options is carried out in [19] and [20]. Additionally, some relevant references that study real options in electricity markets are shown in [21] and [22].

In this paper, we describe electricity options as instruments to manage the two main risks faced by power producers: price and production-availability risks. For this purpose, we describe a multi-stage stochastic programming model that enables a risk-averse power producer to decide its optimal portfolio of forward contracts and options taking into account the pool price volatility and its forced outage rate.

The rest of this paper is organized as follows. Section 2 describes the main characteristics of electricity options. The optimization problem proposed to determine option contracting decisions is described in Section 3. Section 4 shows the capabilities of options to hedge against price and availability risks through two illustrative examples. Section 5 concludes the paper. Finally, the multi-stage stochastic problem is formulated in detail in the Appendix.

\section{Electricity options}

Formally, an option is an agreement which gives the buyer the right, but not the obligation, to sell/buy a certain amount of electricity during a specified future time period, referred to as the delivery period, and at a fixed price called the strike price. Needless to say, buying an option has an additional cost (unlike a forward contract) called the option price, which has to be paid even if the option is not exercised. Depending on whether an option can be exercised on any business day up to and including the expiration date or only on the expiration date itself, options are classified into American and European options, respectively [23]. Due to the more flexibility offered by American options, their option prices are usually higher than those of European options.

There are two main types of options: calls and puts. A call option gives its holder the right to buy a given amount of electricity at the strike price. Conversely, a put option gives its holder the right to sell a given amount electricity at the strike price. There are two sides to every option contract. On one side is the agent that takes the long position, i.e., it purchases either a put or a call option and therefore, the right to sell or buy the underlying commodity at the strike price, respectively. On the other side is the agent that assumes a short position by selling either a put or call option and thus undertaking the obligation to buy or sell, respectively, the underlying commodity at the strike price as long as the holder of the option exercises it. By combining both types of options (calls and puts) with both positions (long and short), the four strategies depicted in Fig. 1 can be accomplished. 


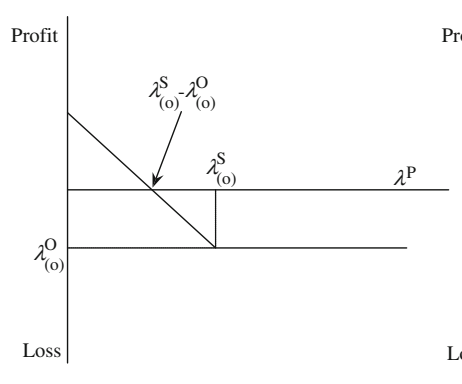

(a) Long put position

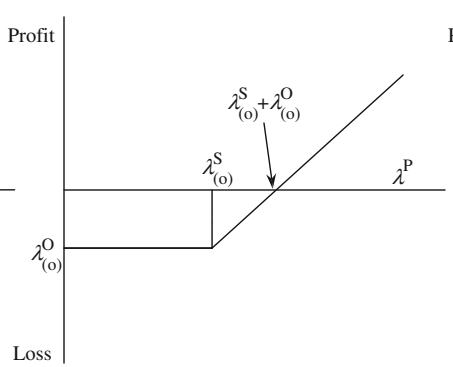

(b) Long call position

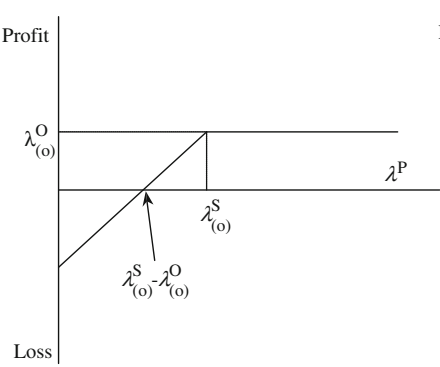

(c) Short put position

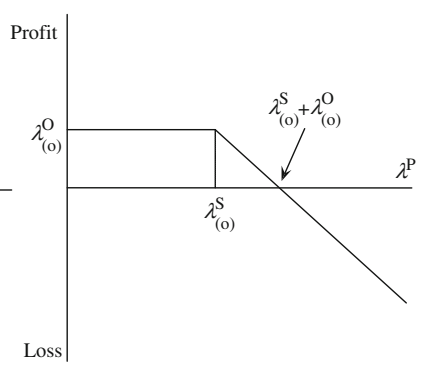

(d) Short call position

Fig. 1 Profit from positions in European options

In Fig. $1, \lambda_{(\mathrm{o})}^{\mathrm{S}}$ and $\lambda_{(\mathrm{o})}^{\mathrm{O}}$ represent the strike price and the option price, respectively. Likewise, $\lambda^{\mathrm{P}}$ stands for the pool price of electricity. Observe that the two long positions limit the possible financial losses to the option price, thus representing the typical behavior of a risk-averse agent. On the other hand, the short positions, correspond to risk-taker agents since in exchange for a given premium, they are willing to assume the risk of the agent that buys the option.

From a hedging perspective, the most relevant feature of options is the delay existing between the time in which the option is signed and its exercising date. The realization of the uncertain parameters between these two decision points allows the option holder to better characterize the uncertain parameters during the option delivery period to decide in an informed manner whether or not to exercise the option. Two illustrative situations are described below.

Firstly, to evaluate how a put option is used to hedge against the pool price risk faced by a power producer, we consider that the generating unit owned by the power producer does not fail. Besides, we assume that the realization of high/low pool prices prior to the exercising time of the option will lead to high/low pool prices during its delivery period. In that case, if electricity prices become high before the expiration date, the producer decides not to exercise the option so as to sell its production in the pool at higher prices. On the other hand, falling pool prices between the purchase and the exercising time of the option would encourage the power producer to exercise the put option to sell electricity at the pre-specified strike price, which will be probably higher than the average pool price realization during the delivery period of the option. In this way, the acquisition of the put option allows the producer to hedge against the risk corresponding to the high volatile prices.

Secondly, we analyze how a call option to buy electricity reduces the availability risk of power producers. Considering that a power producer has signed a forward contract to sell electricity and a call option to have the right to buy electricity during the same delivery period. In that case, if the generating unit owned by the producer fails just before the delivery period of both contracts and the pool price is expected to be high, the producer can exercise the call option to buy electricity. This way, the producer can comply with its contracting selling obligation by buying the electricity through the call option at the strike price, which will be probably lower than the average pool price during the delivery period. On the other hand, if either the generating unit does not fail or the pool prices are expected to decrease below the strike price, the call option is not exercised.

The two situations above are representative of how options can be used to reduce both the price and the availability risks faced by power producers. Note, however, that the flexibility provided by options involves the payment of the option price, which has to be paid by the producer regardless of whether or not the option is exercised. Therefore, a power producer has to decide, the acquisition of a put/ call option given its strike and option prices according to the pool price variability, its availability parameters and risk aversion level. Note also that while forward contracts and insurances are derivatives that reduce either the price or the availability risk, respectively, electricity options are financial derivatives that can be used by power producers to hedge against both price and availability risk.

\section{Model analyses}

\subsection{Assumptions}

The following simplifying assumptions are considered to formulate a multi-stage stochastic model to determine the optimal forward and option contracts for a risk-averse power producer:

1) The generating units owned by the power producer are dispachable thermal units, whose cost is modeled by a piecewise linear function.

2) The power producer can sell its production in the pool at volatile prices, or at fixed prices through forward 
contracts or options in the future market. For the sake of clarity, the arbitrage between these markets is avoided in the proposed model.

3) Option and forward contract prices are not affected by the decisions of the power producer, which is assumed to behave as a price-taker.

4) Two uncorrelated sources of uncertainty are considered, namely the pool price and the availability of generating units. These stochastic parameters are characterized by a scenario tree.

5) Although both physical and financial options are available in electricity markets, due to the energyoriented approach of this paper, all considered options imply the physical delivery of the energy.

6) The power producer is assumed to be risk-averse and therefore, only the purchase (not the selling) of put and call options are considered.

\subsection{Decision framework and uncertainty description}

Decisions related to electricity options are made at different stages. Firstly, the producer has to decide whether or not to sell/buy electricity through a given option, and subsequently, if the option has been purchased, the producer has to decide whether or not it is exercised. Since we consider European options, this second decision has to be made on a given date. Therefore, the study horizon is naturally divided into two periods and three stages, as shown in Fig. 2.

In two-stage stochastic problems, some decisions (hereand-now decisions) are made before the uncertain parameters are known; while other decisions (wait-and-see decisions) are delayed until the uncertain outcomes are disclosed [24]. A model for dealing with multi-stage recourse problems, in which this "decide-observe-decide" pattern is repeated more than once, is therefore proven to be an effective mathematical tool to determine option purchases in electricity markets.

The choice of a multi-stage stochastic programming framework to model options does not only modify the way in which variables and constraints are defined, but also changes the method to generate the scenarios representing the uncertain parameters involved in the model. That is, the knowledge of the realization of a stochastic process during Period 1 has to be properly accounted for to produce the

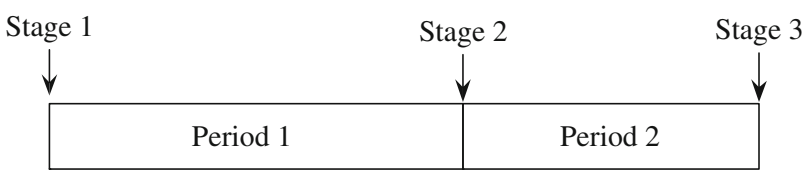

Fig. 2 Time horizon and stages for option contracting scenario set representing the uncertainty of that stochastic process during Period 2.

In this respect, Fig. 3 shows an illustrative scenario tree for a three-stage stochastic problem. Each branch represents the realization of the stochastic processes between two consecutive stages. For example, every branch between Stages 1 and 2 corresponds to a possible realization of the pool price and the unit availability during Period 1. Likewise, nodes correspond to the decisions to be made at each stage.

The three-stage stochastic programming model considered in this paper is described in a precise mathematical form in the Appendix.

In short, availability scenarios are built as follows: firstly, a scenario set representing the availability of the generating units during Period 1 is generated according to the procedure explained, as shown in [25]; then, for each scenario generated for Period 1, a new availability scenario set for Period 2 is built considering the status of the unit in the last hour of Period 1 as its initial status at the beginning of Period 2.

Likewise, pool price scenarios are built as follows: a scenario set representing the pool price during Period 1 is generated, for instance, using an ARIMA model adjusted using historical data [26]. Then, the values of each pool price scenario for Period 1 are taken as certain and introduced into the ARIMA model to generate each scenario set for Period 2. This way, it is more likely that a scenario of high/low pool prices during Period 1 gives rise to a scenario set of high/low prices during Period 2.

\section{Example}

This section is devoted to explaining how put and call options reduce both the price and the availability risks faced by power producers using two illustrative examples.

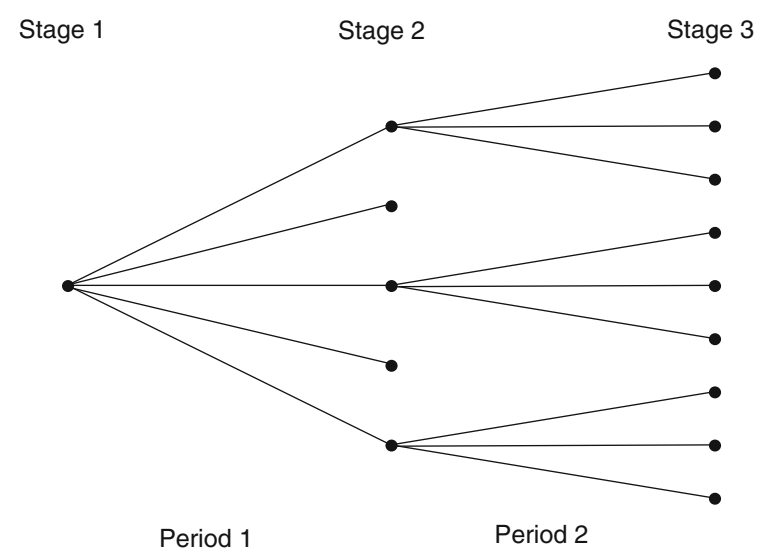

Fig. 3 Three-stage scenario tree for option contracting 
In Example 1, a non-failing generating unit is considered to show the advantages of selling electricity through a put option in order to reduce the price risk. In Example 2, we explore the possibility of hedging against the availability risk using a call option to buy electricity.

For the sake of simplicity, the study horizon covers two hours in both cases. Moreover, for both put and call options, the decision framework (depicted in Fig. 4) is identical. At the beginning of the study horizon, and facing the uncertainty involved in the model for the following two hours, the power producer has to decide whether or not to acquire a given option whose delivery period spans Hour 2 . Then, depending on the realization of the uncertain parameters during Hour 1, the power producer has to decide whether or not to exercise the option at the beginning of the second hour. For illustration purposes, the power producer only owns one 100-MW generating unit with a linear cost of $12 € / \mathrm{MWh}$ and zero minimum power output.

\subsection{Example 1: put options to hedge against price risk}

The aim of this first example is to illustrate how put options can reduce the price risk faced by power producers. For the sake of simplicity, a failure free generating unit is considered. The variability of the pool price throughout the two-hour study horizon is characterized by the four scenarios, as depicted in Fig. 5, where the price realization is indicated in each branch followed by the associated probability in parentheses. Note that the realization of high/low prices during Hour 1 gives rise to the high/low prices during Hour 2.

In order to highlight the major features of an option as a mechanism to hedge against price risk, we consider the following three cases:

1) The power producer sells all its production in the pool at variable prices. In this case, the producer does not sell electricity during these hours in which the pool price happens to be lower than its production cost, i.e., $12 € / M W h$.

2) The producer sells its production through a forward contract that spans the second hour of the study horizon. During the first hour, the producer still has to sell its electricity in the pool at variable prices. In order to obtain unbiased results, the price of the

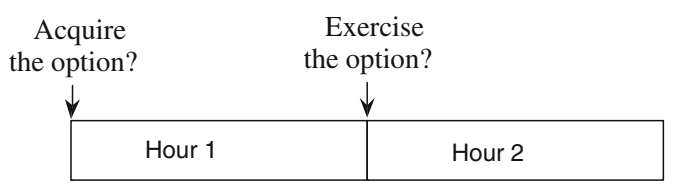

Fig. 4 Decision framework (Example)

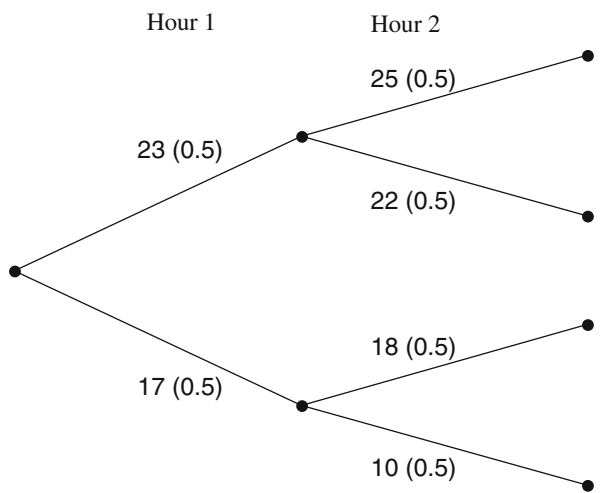

Fig. 5 Pool price scenario tree (Example 1)

forward contract is set to the average pool price during the second hour, i.e., $18.75 € / \mathrm{MWh}$.

3) The producer acquires a put option to sell $100 \mathrm{MW}$ during the second hour. The strike price of the option is also set to $18.75 € / \mathrm{MWh}$. However, regardless of whether the option is exercised or not, the producer has to pay the option price, which is assumed here to be equal to $1 € / \mathrm{MWh}$ for illustration purposes. As opposed to selling electricity through forward contracts, which necessarily implies the delivery of the agreed power level, the put option allows the producer to postpone its decisions related to the sale of its production until additional information becomes available. Being so, the producer exercises the option if the price during the first hour comes down to $17 € / \mathrm{MWh}$ since prices during the second hour are foreseen to be lower than the strike price of the option (18.75 €/ $\mathrm{MWh}$ ). On the other hand, if the price during the first hour happens to be $23 € / \mathrm{MWh}$, the option is not exercised in the hope of selling the production at prices higher than the strike price during the second hour.

Table 1 provides the profit distribution as well as the expected profit for the three cases described above. Observe that even though the strike price of the put option is equal to the average pool price and the price of the forward contract, the power producer obtains the highest expected profit if its production in Hour 2 is sold through the put option. Note that for scenarios $\omega_{1}$ and $\omega_{2}$, the producer makes a profit almost as high as that obtained if the production is directly sold in the pool by not exercising the option. The difference between both profits is due to the cost of the option. On the other hand, the producer exercises the option for $\omega_{3}$ and $\omega_{4}$, thus obtaining a profit almost as high as that achieved if its production is sold through the forward contract. Again, the difference between both profits stems from the cost of the option. 
Observe that selling electricity through a put option allows the power producer to include additional information (pool price during Hour 1) into its decision process to obtain a higher expected profit, and thus hedging against price risk.

Note that the expected profit improvement achieved by the producer if the option is acquired is due to two reasons. The first reason is the fact that, unlike forward contracts, options themselves allow the producer to postpone its selling decisions. The second reason is that the procedure to generate scenarios that characterize the stochastic process involved (the pool price in this example) can use the information revealed during the first hour to generate more accurate price scenarios for the second hour, i.e., high/low prices during the first hour lead to high/low prices during the second hour. If this condition is not satisfied, postponed decisions would be made without new information and therefore, the acquisition of the put option to sell electricity would be pointless.

For illustration purposes, the results presented in this section have been obtained by fixing the electricity sold in the pool, through the forward contract, or the put option to the capacity of the generating unit for each case. However, in real-world cases, the optimal strategy would involve the combined participation of the power producer in these three markets. The optimal quantities to be allocated in each market are computed by solving the multi-stage stochastic programming (A1a)-(A1r) provided in the Appendix A.

\subsection{Example 2: call options to hedge against availability risk}

In this example, we consider a call option that allows a generating unit subject to failure, in exchange for the option cost, to decide whether or not to buy electricity at the strike price during the second hour of the study horizon. Exercising the option depends on the realization of the stochastic processes during Hour 1, i.e., the pool price and the unit availability.

To characterize the pool price during the two-hour horizon, the four price scenarios depicted in Fig. 5 are

Table 1 Producer profit distribution (Example 1)

\begin{tabular}{lrlll}
\hline \# Scenario & Pool & Forward & Option & $\pi_{\omega}$ \\
\hline$\omega_{1}$ & 2,400 & 1,775 & 2,300 & 0.25 \\
$\omega_{2}$ & 2,100 & 1,775 & 2,000 & 0.25 \\
$\omega_{3}$ & 1,100 & 1,175 & 1,075 & 0.25 \\
$\omega_{4}$ & 500 & 1,175 & 1,075 & 0.25 \\
$\bar{\Pi}(€)$ & 1,525 & 1,475 & $\mathbf{1 , 6 1 2 . 5}$ & \\
\hline
\end{tabular}

Note: $\pi_{\omega}$ is the probability of occurrence of scenario $\omega$; $\bar{\Pi}$ is the average of the total producer profit considered. Moreover, the MTTF (mean time to failure) and the MTTR (mean time to repair) of the generating unit are equal to $2 \mathrm{~h}$ and $1 \mathrm{~h}$, respectively. According to these values, Fig. 6 provides the availability scenario tree of the unit during the study horizon considering that the unit is initially online. A relevant observation that can be made from this figure is the effect of the unit status during the first hour on the probability that the unit is forced out during the second hour. That is, the probability that the unit is forced out during Hour 2 is equal to 0.26 or 0.41 depending on whether or not the generating unit is available during Hour 1, respectively.

Note that a producer that sells its production in the pool during the two hours of the study horizon does not have any contracting obligation to sell electricity. In contrast, as previously discussed, selling electricity through a forward contract necessarily involves the purchase of the agreed energy in the pool during those time steps in which the generating unit is forced out. For this reason, in this example, we consider a power producer that sells its production through a forward contract spanning the second hour, whose price is fixed to the average pool price during this period (18.75 €/MWh), and that evaluates the possibility of acquiring a call option to reduce the financial losses associated with unexpected unit failures. In doing so, if scenarios characterized by unit failures and high pool prices are likely, the producer generally exercises the option to buy electricity at a lower price. In this example, the option strike price is set to be $15 € / \mathrm{MWh}$ (a price higher than the unit production cost and lower than the forward contract price) and its option price is set to be $0.1 € / \mathrm{MWh}$ for illustration purposes.

The probability mass functions of the producer profit with and without a call option are shown in Fig. 7. We observe that the call option eliminates the possibility of having negative profits without significantly changing the probabilities of occurrence of the highest profits of the distribution. This is so because the producer exercises the option if in the first hour the price is equal to $23 € / \mathrm{MWh}$

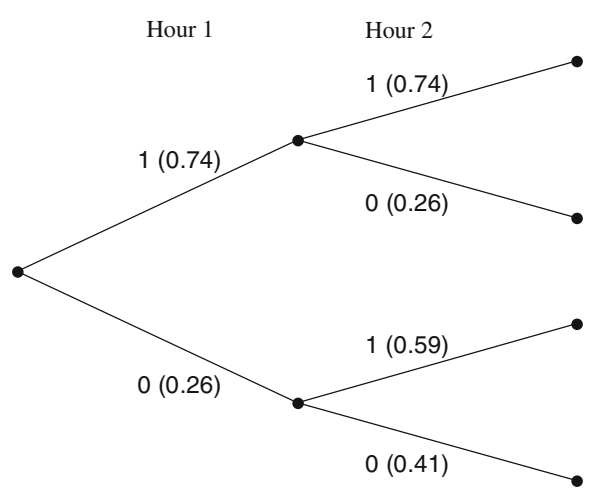

Fig. 6 Availability scenario tree (Example 2) 


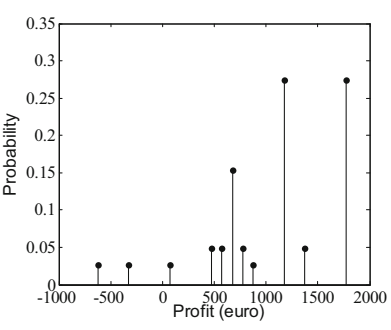

(a) Without call option

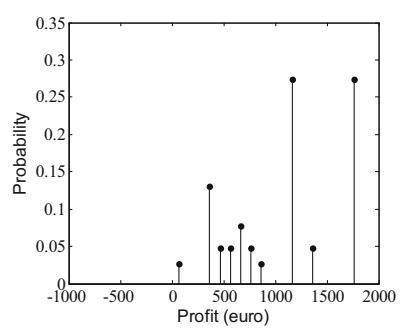

(b) With call option
Fig. 7 Probability mass functions (Example 2)

and the unit is unavailable. Moreover, the producer expected profit obtained depending on whether or not the call option is signed is $€ 1,077.5$ and $€ 1,065.2$, respectively.

In short, this example illustrates that the acquisition of a call option can reduce the availability risk of generating units by allowing a power producer to sell contracting obligations to buy electricity at a fixed price, when there exists a high probability of suffering from unexpected unit failures.

As in the previous example, the quantity corresponding to the call option is fixed to the capacity of the generation unit for the sake of illustration. It is therefore worth mentioning that the optimal amount of call options to be acquired by a power producer to hedge against its availability risk should be determined by solving the optimization model (A1a)-(A1r) provided in the Appendix.

\section{Conclusion}

Power producers face uncertainties related to price variability and production availability when trading in electricity markets. Thus, power producers must make their decisions not only to maximize the expected profit but also to reduce the profit variability caused by the uncertainty involved. While hedging against price risk through forward contracts increases the availability risk due to unexpected unit failures, electricity options allow producers to delay decisions on selling or buying a given amount of electricity at a fixed price until the beginning of the delivery period of the option. This postponement gives the holder of the option additional information to make better decisions.

Two illustrative examples are employed in this tutorial to explain how the acquisition of both put and call electricity options reduces the price and availability risks faced by power producers, respectively. Besides, the comprehensive three-stage stochastic formulation required to determine the optimal option contracting strategy of a riskaverse power producer is provided in the Appendix A.
Open Access This article is distributed under the terms of the Creative Commons Attribution License which permits any use, distribution, and reproduction in any medium, provided the original author(s) and the source are credited.

\section{Appendix A}

\section{Formulation}

The multi-stage stochastic formulation of the risk-constrained profit maximization problem for a power producer to decide on forward and option contracts is described as follows:

$\max \xi-\frac{1}{1-\alpha} \sum_{\omega} \pi_{\omega} \eta_{\omega}$

Subject to

$\Pi_{\omega}=\Pi_{\omega}^{\mathrm{P}}+\Pi^{\mathrm{F}}+\Pi_{\omega}^{\mathrm{O}}-C_{\omega}^{\mathrm{G}}, \quad \forall \omega$

$\Pi_{\omega}^{\mathrm{P}}=\sum_{t} \lambda_{\omega t}^{\mathrm{P}} P_{\omega t}^{\mathrm{P}} L_{t}, \quad \forall \omega$

$\Pi^{\mathrm{F}}=\sum_{c} \lambda_{c} P_{c} L_{c}$

$\Pi_{\omega}^{\mathrm{O}}=\sum_{o}\left(l_{o} y_{\omega o} \lambda_{o}^{\mathrm{S}}-\lambda_{o}^{\mathrm{O}}\right) P_{o} L_{o}, \quad \forall \omega$

$C_{\omega}^{\mathrm{G}}=\sum_{i, t}\left(A_{i} u_{i \omega t}+\sum_{b} \lambda_{i b} P_{i \omega t b}^{\mathrm{G}}\right) L_{t}, \quad \forall \omega$

$P_{i \omega t}^{\mathrm{G}}=u_{i \omega t} P_{i}^{\min }+\sum_{b} P_{i \omega t b}^{\mathrm{G}}, \quad \forall i, \forall \omega \forall t$

$u_{i \omega t} k_{i \omega t} P_{i}^{\min } \leq P_{i \omega t}^{\mathrm{G}} \leq u_{i \omega t} k_{i \omega t} P_{i}^{\max }, \quad \forall i, \forall \omega, \forall t$

$0 \leq P_{i \omega t b_{1}}^{\mathrm{G}} \leq P_{i b_{1}}^{\max }-P_{i}^{\mathrm{min}}, \quad \forall i, \forall \omega, \forall t$

$0 \leq P_{i \omega t b}^{\mathrm{G}} \leq P_{i b}^{\max }-P_{i b-1}^{\min }, \quad \forall i, \forall \omega, \forall t, \forall b$

$\sum_{i} P_{i \omega t}^{\mathrm{G}}=P_{\omega t}^{\mathrm{P}}+\sum_{c \in F_{t}} P_{c}+\sum_{o \in O_{t}} l_{o} y_{\omega o} P_{o}, \quad \forall \omega, \forall t$

$\sum_{i}\left(k_{i \omega t}-1\right) P_{i}^{\max } \leq P_{\omega t}^{P}, \quad \forall \omega, \forall t$

$\sum_{i} P_{i \omega t}^{\mathrm{G}}+\sum_{o: l_{o}=-1} y_{\omega o} P_{o} \leq \sum_{i} P_{i}^{\max }, \quad \forall \omega, \forall t$

$-\Pi_{\omega}+\xi-\eta_{\omega} \leq 0, \quad \forall \omega$

$y_{(o, \omega)}=y_{\left(o, \omega^{\prime}\right)} \quad \forall o, \forall \omega, \omega^{\prime}: \omega^{\prime} \in S_{(\omega)}$

$S_{(\omega)}=\left\{\omega^{\prime}: \lambda_{\left(\omega^{\prime}, t\right)}^{\mathrm{P}}=\lambda_{(\omega, t)}^{\mathrm{P}}, k_{\left(i, \omega^{\prime}, t\right)}=k_{(i, \omega, t)}, \forall i, \forall t\right\}$

$\eta_{\omega}, P_{c}, P_{o} \geq 0$

$u_{i \omega t}, y_{\omega o} \in\{0,1\}$ 
where $\pi_{\omega}$ is the probability of occurrence of scenario $\omega ; \xi$ is the auxiliary variable used to calculate the CvaR; $\alpha$ is the risk aversion level of the power producer; $\eta_{\omega}$ is the auxiliary variable used to calculate the $\mathrm{CvaR} ; \Pi_{\omega}$ is the total producer profit in scenario; $\Pi_{\omega}^{\mathrm{P}}$ is the pool revenue of the producer in scenario $\omega(€)$; $\Pi^{\mathrm{F}}$ is the forward contract revenue of the producer $(€)$; $\Pi_{\omega}^{\mathrm{O}}$ is the option revenue of the producer in scenario $\omega(€) ; \lambda_{\omega t}^{\mathrm{P}}$ is the pool price in time step $t$ and scenario $\omega(€ / \mathrm{MWh}) ; P_{\omega t}^{\mathrm{P}}$ is the power sold in the pool in time $t$ and scenario $\omega(\mathrm{MW}) ; L_{t}$ is the duration of time step $t(\mathrm{~h}) ; \lambda_{c}$ is the energy price of forward contract $c$ (€/MWh); $P_{c}$ is the power sold through forward contract $c$ (MW); $L_{c}$ is the duration of forward contract $c(\mathrm{~h}) ; l_{o}$ is the parameter equal to 1 if option $o$ is a put option, and to -1 for a call option; $y_{\omega o}$ is the binary variable that is equal to 1 if the producer exercises the option $o$ in scenario, and 0 otherwise; $\lambda_{o}^{\mathrm{S}}$ is the strike price of put/call option contract $o(€ / \mathrm{MWh}) ; \lambda_{o}^{\mathrm{O}}$ is the option price of put/call option contract $o(€ / \mathrm{MWh}) ; P_{o}$ is the power traded through put/call option contract $o(\mathrm{MW}) ; L_{o}$ is the duration of put/call option contract $o(\mathrm{~h}) ; C_{\omega}^{\mathrm{G}}$ is the total production cost in scenario $\omega(€) ; A_{i}$ is the coefficient of the cost function of unit $i(€ / \mathrm{h}) ; u_{i \omega t}$ is the binary variable equal to 1 if unit $i$ is online during time step $t$ and scenario $\omega ; \lambda_{i b}$ is the slope of the $b$ th power block of unit $i(€ / \mathrm{MW}) ; P_{i \omega t b}^{\mathrm{G}}$ is the power generated from the $b$-th power block of unit $i$ in time step $t$ and scenario $\omega(\mathrm{MW}) ; b_{1}$ is the first block in which the cost generation function has been approximated by a piece-wise linear function; $P_{i \omega t}^{\mathrm{G}}$ is the production of unit in time $t$ and scenario $\omega$ (MW); $P_{i}^{\min }$ is the minimum power output of generating unit $i(\mathrm{MW}) ; P_{i}^{\max }$ is the capacity of generating unit $i(\mathrm{MW}) ; k_{i \omega t}$ is the availability of unit $i$ in time step $t$ ( 1 if available and 0 otherwise); $F_{t}$ is the set of forward contracts $c$ available during time step $t ; O_{t}$ is the set of option contracts available during time step $t ; S_{(\omega)}$ is the scenario set with uncertain parameter values for Period 1 equal to those corresponding to scenario $\omega$.

Objective function (A1a) is the Conditional Value-atRisk $(\mathrm{CVaR})$ of the profit probability distribution of the producer for a confidence level $\alpha$ [27]. The CVaR for a confidence level $\alpha$ of a profit distribution is defined as the conditional expectation of the values of the probability distribution lower than the $\alpha$-quantile. In other words, the CVaR represents the expected value of the $(1-\alpha) \%$ worst profits. Namely, the CVaR for $\alpha=0$ corresponds to the expected value of the entire distribution. Likewise, if $\alpha=0.9$, the CVaR is determined as the average value of the $10 \%$ lowest profits.

Equation (A1b) expresses the total profit achieved by the producer in each scenario $\omega\left(\Pi_{\omega}\right)$ as the sum of the revenue obtained in the pool $\left(\Pi_{\omega}^{\mathrm{P}}\right)$, the revenue from forward contracts $\left(\Pi^{\mathrm{F}}\right)$ and the option revenue $\left(\Pi_{\omega}^{\mathrm{O}}\right)$ minus the production cost $\left(C_{\omega}^{\mathrm{G}}\right)$. Equation (A1c) expresses the profit in the pool as the summation over all time periods of the pool price times the power sold times the period duration. The revenue corresponding to forward contracts is calculated in (A1d) as the summation over all contracts of the contract price times the power sold times the contract duration. The option revenue of (A1e) has two terms. The second term corresponds to the cost of the option, which has to be paid regardless of whether or not the option is exercised, and that is computed as the product of the option price times, the option power times and the contract duration. The first term corresponds to the option revenue that is computed as the strike price times, the option power times and the contract duration times, a binary variable $\left(y_{\omega o}\right)$ that is equal to 1 if the option is exercised, and to 0 otherwise. As stated by (A1f), the production cost is equal to the summation over time and over production units of the no-load cost plus the variable cost, being this variable cost approximated through a piecewise linear function.

Constraint (A1g) defines the generated power as the minimum power of each unit plus the summation over the production blocks $b$ of the generated power in each block. The power generated by each unit is bounded below and above by its minimum power output and its capacity, respectively, through constraint $(\mathrm{A} 1 \mathrm{~h})$. Note that if a unit suffers an unexpected failure $\left(k_{i \omega t}=0\right)$, its power output is equal to $0 \mathrm{MW}$. Additionally, (A1i) and (A1j) bound each block $b$. Constraint (A1k) enforces that the generated power is equal to the power sold in the pool, through forward contracts, and through option contracts. The arbitrage between the pool and the futures market (forward contracts and options) is avoided by using constraints (A11) and (A1m). Constraint (A11) enforces that the producer can only buy electricity in the pool during those time periods in which one of its production unit is forced out. Likewise, (A1m) enforces that the generated power plus the power bought through call options cannot be higher than the total capacity of the generating units. To maximize the CVaR of the profit distribution, (A1n) is needed. Constraint (A1p) is non-anticipativity conditions which impose that decisions regarding the exercise of options depends on scenario realizations during Period 1, but they are unique regarding decisions throughout Period 2. Constraints (A1q) and (A1r) are positive and binary variable declarations, respectively.

\section{References}

[1] Benini M, Marracci M, Pelacchi P et al (2002) Day-ahead market price volatility analysis in deregulated electricity 
markets. In: Proceedings of the IEEE Power Engineering Society Summer Meeting, Vol 3, Chicago, IL, USA, 21-25 Jul 2002, pp 1354-1359

[2] Paravan D, Sheble GB, Golob R (2004) Price and volume risk management for power producers. In: Proceedings of the International Conference on Probabilistic Methods Applied to Power Systems (PMAPS'04), Ames, IA, USA, 12-14 Sept 2004, pp 699-704

[3] Deng SJ, Oren SS (2006) Electricity derivatives and risk management. Energy 31(6):940-953

[4] Conejo AJ, García-Bertrand R, Carrión M et al (2008) Optimal involvement in futures markets of a power producer. IEEE Trans Power Syst 23(2):703-711

[5] Pineda S, Conejo AJ, Carrión M (2008) Impact of unit failure on forward contracting. IEEE Trans Power Syst 23(4):1768-1775

[6] Pineda S, Conejo AJ, Carrión M (2010) Insuring unit failures in electricity markets. Ener Econ 32(6):1268-1276

[7] Ghosh K, Ramesh VC (1997) An options model for electric power markets. Int J Electr Power 19(2):75-85

[8] Zhang Q, Zhou H (2004) Analysis of forward option trades in electricity markets. In: Proceedings of the IEEE International Conference on Electric Utility Deregulation, Restructuring and Power Technologies (DRPT'04), Vol 2, Hong Kong, China, 5-8 Apr 2004, pp 500-504

[9] Wu HC (2004) Pricing European options based on the fuzzy pattern of Black-Scholes formula. Comput Oper Res 31(7): 1069-1081

[10] Lane DW, Richter CW, Sheble GB (2000) Modeling and evaluating electricity options markets with intelligent agents. In: Proceedings of the IEEE International Conference on Electric Utility Deregulation, Restructuring and Power Technologies (DRPT'00), London, UK, 4-7 Apr 2000, pp 203-208

[11] Richter CW, Shebe GB (1998) Bidding strategies that minimize risk with options and futures contracts. In: Proceedings of the 1998 American Power Conference, Vol 60, Chicago, IL, USA, 14-16 Apr 1998, pp 399-404

[12] Anderson EJ, Xu H (2006) Optimal supply functions in electricity markets with option contracts and non-smooth costs. Math Method Oper Res 63(3):387-411

[13] Oum Y, Oren SS, Deng SJ (2006) Hedging quantity risks with standard power options in a competitive wholesale electricity market. Nav Res Logist 53(7):697-712

[14] Oum Y, Oren SS (2010) Optimal static hedging of volumetric risk in a competitive wholesale electricity market. Decis Anal $7(1): 107-122$

[15] Bhanot K (2002) Value of an option to purchase electric power: the case of uncertain consumption. Energ Econ 24(2):121-137

[16] Chung TS, Zhang SH, Yu CW et al (2003) Electricity market risk management using forward contracts with bilateral options. IEE Proc: Gener Transm Distrib 150(5):588-594

[17] Oren SS (2001) Integrating real and financial options in demandside electricity contracts. Decis Support Syst 30(3):279-288
[18] Spinler S, Huchzermeier A, Kleindorfer P (2003) Risk hedging via options contracts for physical delivery. OR Spectrum 25(3):379-395

[19] Haarbücker G, Kuhn D (2009) Valuation of electricity swing options by multistage stochastic programming. Automatica 45(4):889-899

[20] Keppo J (2004) Pricing of electricity swing options. J Deriv 11(3):26-43

[21] Deng SJ, Johnson B, Sogomonian A (2001) Exotic electricity options and the valuation of electricity generation and transmission assets. Decis Support Syst 30(3):383-392

[22] Denton M, Palmer A, Masiello R et al (2003) Managing market risk in energy. IEEE Trans Power Syst 18(2):494-502

[23] Hull J (2009) Options, futures and other derivatives. Pearson/ Prentice Hall, Upper Saddle River, NJ, USA

[24] Higle JL (2005) Stochastic programming: optimization when uncertainty matters. In: Tutorials in Operation Research: Emerging Theory, Methods, and Applications: Proceedings of the INFORMS Annual Meeting (INFORMS'05), San Francisco, CA, USA, 13-16 Nov 2005, pp 30-53

[25] Pineda S, Conejo AJ (2012) Managing the financial risks of electricity producers using options. Energ Econ 34(6):2216-2227

[26] Conejo AJ, Contreras J, Espínola R et al (2005) Forecasting electricity prices for a day-ahead pool-based electric energy market. Int J Forecast 21(3):435-462

[27] Rockafellar RT, Uryasev S (2000) Optimization of conditional value-at-risk. J Risk 2(3):21-42

\section{Author Biographies}

Salvador PINEDA (S'07, M'11) received the Ingeniero Industrial degree from the Universidad de Málaga, Málaga, Spain, in 2006, and a Ph.D. degree in Electrical Engineering from the University of Castilla-La Mancha, Ciudad Real, Spain, in 2011. He is currently an assistant professor at the Center for Electric Technology (CET) at the Technical University of Denmark, Kgs. Lyngby, Denmark. His research interests are in the fields of power system economics, renewables integration, reliability, optimization, stochastic programming, and electricity markets.

Antonio J. CONEJO (F'04) received the M.S. degree from the Massachusetts Institute of Technology, Cambridge, in 1987 and the $\mathrm{Ph} . \mathrm{D}$. degree from the Royal Institute of Technology, Stockholm, Sweden, in 1990. He is currently a full Professor at the Universidad de Castilla-La Mancha, Ciudad Real, Spain. His research interests include control, operations, planning and economics of electric energy systems, as well as statistics and optimization theory and its applications. 